\title{
FATE OF AGRICULTURAL AREAS OF KAILALI DISTRICT OF NEPAL: A TEMPORAL LAND USE LAND COVER CHANGE (LUCC) ANALYSIS.
}

\author{
Niraj KC ${ }^{1}$, Lawaj Thapa ${ }^{1}$, Dericks Praise Shukla ${ }^{1 *}$ \\ ${ }^{1}$ School of Engineering, IIT Mandi, India (d18058@ students.iitmandi.ac.in; dericks@iitmandi.ac.in)
}

Commission III, WG III/7

KEY WORDS: Supervised Classification, LULC mapping, Temporal change analysis, Accuracy Assessment, Urbanisation

\begin{abstract}
:
Changes of agricultural land into non-agricultural land is the main issue of increasing population and urbanization. The objective of this paper is to identify the various land resources and its changes into other Land Use Land Cover (LULC) type. LANDSAT satellite data for 1990, 2000, 2010 and 2018 years of Kailali district Nepal was acquired for supervised LULC mapping and change analysis using ENVI 5.4 software. Sentinel-2 and Google earth satellite data were used for the accuracy assessment of the LULC map. The time-series data analysis from 1990-2000-2010-2018 shows major changes in vegetation and agriculture. The changes in LULC show that settlement and bare land is continuously increasing throughout these years. The change in land use and land cover during the period of 1990-2018 shows that the settlement area is increased by 204\%; and agriculture is decreased by $57 \%$. The fluctuating behavior of vegetation, agriculture and water bodies in which the areas decrease and increase over the selected periods is due to natural calamities and migration of the local population. This shows that human influence on the land resources is accelerating and leading to a deterioration of agricultural land. Thus effective agricultural management practices and policies should be carried out at the government level for minimizing land resources degradation by the human-induced impact.
\end{abstract}

\section{INTRODUCTION}

The land occupied by the population for their specific purposes such as farming, settlement can be defined as land use (FAO, 1976; Stomph et al.,1994); while the land cover is defined as the biophysical condition of the earth surface and its instant subsurface (Herold et al., 2003). Land cover includes features such as grassland, forest, concrete, etc. whereas land use refers intention connected with that land cover such as raising cattle, urban planning, etc. (Zubair, 2006). Land use is related to land cover in various aspects such as forest used for a combination of timbering, the farming system combined with cultivable land, settlement, pasture land, etc. (Zubair, 2006).

The major issues in global sustainable development are land use and land cover changes over time (Guan et al., 2011; Halmy et al., 2015). Land use and land cover mapping and decadal change analysis depend upon the spatial and temporal level of analysis. A high level of spatial and temporal detail is not sufficient for detecting small changes. The detection of a piece of agricultural land converted into an airport cannot be visible at the national level (small scale) (Jat et al., 2008). The longterm phenomenon of land use and land cover change is not visible in a short time since the conversion of agriculture land into urban cannot be detected within 1 or 3 years of a time interval as it requires a long time interval gap and large scale data. The land use and land cover changes are strongly influenced by rapid urbanization (Dadras et al., 2015). Urbanization is affected by human influences, socioeconomic and physical factors which result in various consequences including deforestation, destruction of agricultural lands, and conversion of bare and fallow lands into human settlements (Dadras et al., 2015).
The traditional method of geospatial techniques of land use and land cover mapping, monitoring and analysing of LULC changes are very time consuming (Martinuzzi et al., 2007). The current available geospatial techniques are very reliable and fast for recording locational data and attributed datasets. Thus, the technique is capable to integrate location and attributed datasets to make LULC maps, which play an important role in land use management, monitoring and disseminating land-related information at different levels (Joshi, 2016).

Remote sensing (RS) and Geographic Information system (GIS) techniques have been widely used to classify LULC and to enable calculation of its matching area distribution (Lillesand and Kiefer, 2015). The assurance of increase and decrease of land use and land cover change (LUCC) at different periods can be easily determined once RS and GIS results integrate with ground measurements (DeFries et al., 2004). The capability and strength of methods provide correct locational information, inaccessible LULC information and repetitive coverage of large areas (Zubair, 2006). The importance of the up-to-date LULC information system is to understand and approximate different environmental, socio-economic and biophysical significances of these decadal LULC changes (Wilson and Chakraborty, 2013; Williams, and Schirmer, 2012). The LULC information system can be used by different levels of government structures, landuse managers, planners and policymakers to monitor how the land can be used for sustainable development and land use management efficiently and effectively (Foley et al., 2005; Meyer and Turner, 1992).

LULC changes for the urban environment is highly affected by anthropogenic activities and habitat fragmentation. Thus, we

\footnotetext{
* Corresponding author
} 
need to have better thinking of mapping and monitoring LULC changes in urban areas (DeFries et al., 2004). The process of observing and identifying the major variation of targeted land features and their dynamics for different periods is termed as pattern analysis (Martinuzzi et al., 2007). The pattern analysis is done to identify the geographical differences in a repetitive time. The pattern analysis is applicable in various fields such as urban sprawl, habitat fragmentation coastal change, rate of deforestation, etc. Habitat fragmentation is the main cause of land degradation or alteration of land resources from one circumstance to another. The pattern analysis of habitat fragmentation and its causes help in formulating appropriate conservation measures for any region and it is one of the main techniques to recognize and quantify land-use and land-cover change (LUCC). The pattern analysis of LUCC in mountainous areas involves the detection and mapping of fragmented LULC, soil loss estimation and risk assessment (Taubenböck et al., 2009). Due to global dynamics and Spatio-temporal variations, the LULC mapping and pattern analysis had become the main research topic to analyse the changing trends in geographical space (Mas, 1999).

The objective of this research paper is to understand the Spatiotemporal phenomenon through LULC mapping and change analysis in the Kailali district of Nepal. This paper aims to identify decadal changes in LUCC patterns and analyze the changes in terms of land degradation and habitat fragmentation. The LULC mapping, pattern and trend analysis in the land-use transformations have been studied using remote sensing and GIS techniques. The details of multi-temporal LULC mapping and LUCC analysis of this work will be helpful to policymakers in making policies for better LULC management and effective land-use practices.

\section{MATERIALS AND METHODS}

\subsection{Study Area}

The LULC mapping and LUCC analysis has been carried out in Kailali district of Nepal which is located in far-Western Province-7 having the spatial extent between latitude $28^{\circ} 23^{\prime}$ $36.34125^{\prime \prime} \mathrm{N}$ to $29^{\circ} 4^{\prime} 8.37569^{\prime \prime} \mathrm{N}$ and longitude from $80^{\circ} 28^{\prime}$ 2.64791" E to $81^{\circ} 17^{\prime} 20.71635^{\prime \prime}$ E covering an area of about $3,235 \mathrm{sq} \mathrm{km}$ as shown in Figure 1. The elevation of the district varies from 109 meters in the Terai belt to 1950 meters in the mountainous areas. Nearly $60 \%$ of the study area have elevation below $300 \mathrm{~m}$, making it lower tropical climate; around $26 \%$ area falls under upper tropical climate having the elevation range between $300-1000 \mathrm{~m}$; and the mountainous areas $(1000-2000$ m) falling under sub-tropical climate covers nearly $14 \%$ of the study area (Joshi, 2016). Usually, the district has a mild and warm temperature that varies from a maximum of $43^{\circ} \mathrm{C}$ in summer and a minimum of $5^{\circ} \mathrm{C}$ in winter season with an average annual temperature of $31^{\circ} \mathrm{C}$. Around $65 \%$ of the district is covered by vegetation/ forest and $28 \%$ is covered by cultivated land (Joshi, 2016). The main rivers are Gaurishankar, Likma, Godawari, Karnali, Shivganga, and Patharaiya. Some of the prominent natural lakes of the district are Koilahi, Behadababa, Tilko, Jokhar, and Ghodaghodi that are mostly present in the Tarai region. The district has a total population of about 775,709 in 2011 with $2.29 \%$ population growth rate.

\subsection{Data Used}

The primary data source used for LULC mapping and LUCC analysis is satellite imagery. The study used Landsat 5 , Landsat 8 and Sentinel-2 satellite imagery. The satellite imagery Landsat 5 TM, Landsat 8 OLI and Sentinel-2 MSS of the study area were downloaded from the US Geological Survey image database site (http://earthexplorer.usgs.gov). Sentinel-2 satellite imagery is used for validating classified maps of the years 2018 . The spatial resolution of Sentinel-2 image $(10 \mathrm{~m}, 20 \mathrm{~m})$ is high as compare to Landsat datasets $(15 \mathrm{~m}, 30 \mathrm{~m})$. Topographic map of 1:25000 is downloaded from Mountain of Central Asia Digital Dataset (MCADD) and it is used for satellite image registration with spatial reference system WGS 1984 UTM zone $44 \mathrm{~N}$.

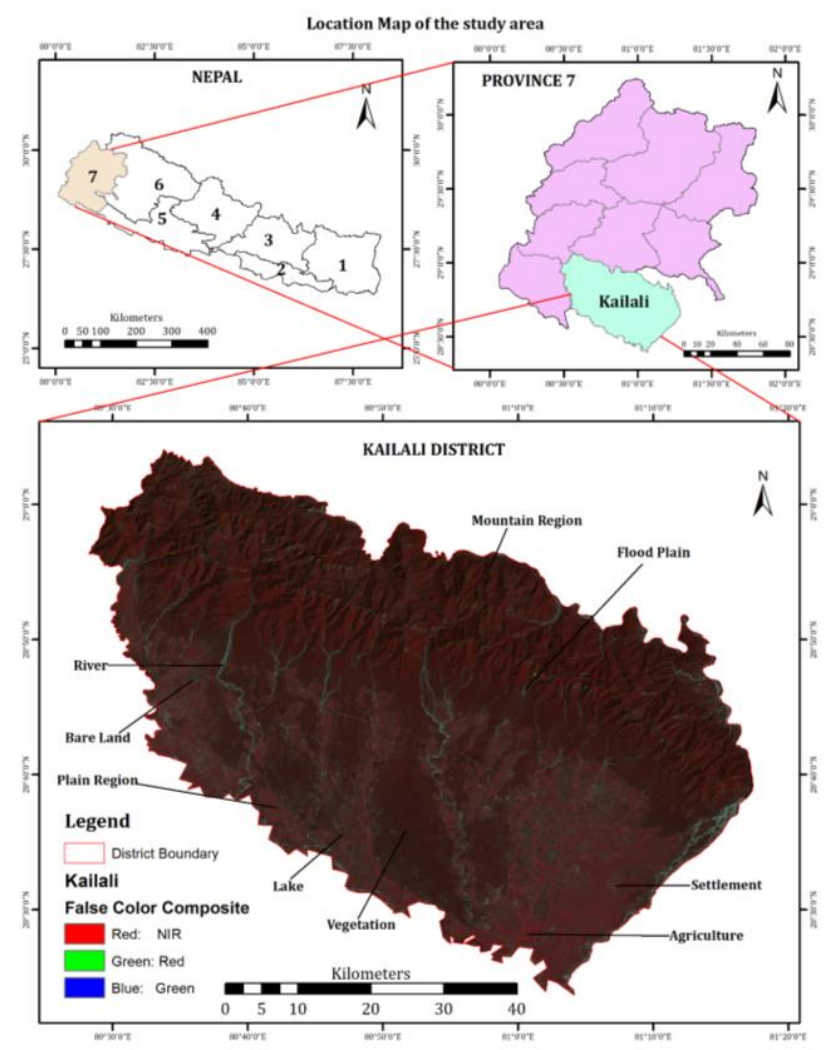

Figure 1: Location map of study area

\subsection{Image Preprocessing}

The downloaded satellite data is pre-processed first before data analysis due to the occurrence of atmospheric effect, topographic effect and geometric effect in the satellite imagery. The topographic correction chosen is sun angle correction which minimizes the effects that occur due to different positions of the sun (i.e. in the morning, noon, evening). Sun angle correction is termed as absolute radiometric correction obtained by dividing top of atmosphere (TOA) correction by solar elevation angle. i.e. (Sine (sun elevation)) (Gupta and Shukla, 2016). The mathematical formula top of atmosphere (TOA) correction is given below:

$$
\boldsymbol{\sigma}=\mathbf{M} * \mathbf{D N}+\mathbf{A}
$$

Where, $\sigma=$ Top of atmosphere correction

M= Band Specific Reflectance Mult_Band

$\mathrm{DN}=$ Digital number values

A= Reflectance_Add_Band 
Band specific reflectance mult_band and reflectance add_band information are obtained from Landsat datasets metadata file. Digital number values are the original downloaded image. Thus, obtained corrected top of atmosphere image was used for topographic correction. The mathematical formula topographic correction is given below:

\section{$\lambda=\sigma / \operatorname{sine}(\theta)$ \\ Where $\lambda=$ Sun angle correction $\sigma=$ Top of atmosphere correction $\boldsymbol{\theta}=$ Sun elevation}

Sun elevation angle is obtained from the Landsat datasets metadata file. Hence, Absolute radiometric correction altered individual pixel values to correct atmospheric and topographic effect occurred in satellite images. Geometric correction refers to minimize the effects occurred due to the altitude and attitude of the sensor. Topographic map of 1:25000 is obtained from Mountain of Central Asia Digital Dataset (MCADD) and it is used for satellite image registration with spatial reference system WGS 1984 UTM zone 44N. Bilinear resampling technique is chosen during the image registration process to maintain root mean square error (RMSE) less than $30 \mathrm{~m}$. The topographic, atmospheric and geometric corrected satellite image is then layer stacked and clipped by polygon file of the study area for automatic feature extraction from satellite imagebased upon similar DN value

\subsection{Image Classification}

Image Classification is the process of extracting different features class from the satellite imagery-based upon similar DN value (Janssen \& Gorte, 2001). The supervised automatic classification method is used for selecting training samples and processing them automatically choosing a maximum likelihood algorithm of supervised classification to prepare the land use and land cover (LULC) map of different years.

\subsection{Accuracy Assessment}

Accuracy assessment plays an important role in any thematic mapping project. It relates the classified image to referenced data (i.e. Ground truth). Ground truth is collected from Google earth to access the accuracy of 1990, 2000 and 2010 classified data because high-resolution imagery is not freely available for those periods. The sentinel-2B satellite of resolution $(10 \mathrm{~m}, 20$ $\mathrm{m})$ datasets available from 2015 onwards is used to validate the 2018 classified data. The accuracy of classified data for 1990 , 2000, 2010 and 2018 is accessed by generating error matrix and calculating kappa statistics. Confusion matrix/ Error matrix is generated to compare 200 random sample points of ground truth data as reference data with classified data of different periods. Error matrix results in overall accuracy, producer accuracy and user accuracy of classified data. Kappa statistics are calculated to understand how closely classified data matched the sample data as ground truth if results close to 1 show truly partial ground condition.

\section{RESULTS AND DISCUSSION}

\subsection{Land Use Land Cover Mapping}

The rationale of the research lies in preparing the LULC map and understanding spatiotemporal conditions through LULC analysis. Figure 2 and figure 3 below shows the resulted LULC map of Kailali district Nepal. The temporal distribution of LULC changes for four decades (1990-2018) is shown in Table 1 . The area occupied by the water bodies in the year 1990 was 6600 ha (2\%) but it decreased in the year 2000 to about 3206 ha $(0.97 \%)$. A similar decreasing trend occurred in the year 2010 in which only 2959 ha $(0.90 \%)$ was occupied by the water bodies whereas the area is about 4969 ha $(1.51 \%)$ in 2018 . In 1990 vegetation covers an area of about 159368 ha (48.39\%) but in 2000 it has an area of about 178541 ha (54.22\%). It shows that from 1990 to 2000 there is an increase in vegetation area. If we observe the area occupied by vegetation in the year 2010 and 2018 there was 167314 ha $(50.81 \%)$ and 176969 $(53.74 \%)$ respectively. This shows a slight increment in vegetation area from 2010 to 2018. The settlement class covered an area of about $4806(1.46 \%)$ in the year 1990, similarly, in the year 2000, 2010 and 2018 covered an area of about $9329(2.83 \%), 11140(3.38 \%)$ and $14625(4.44 \%)$ respectively. This shows the increasing trend throughout the selected years. The bare land occupied an area of about 76577 ha $(23.25 \%), 85595$ ha $(25.99$ ha $), 88784$ ha $(26.96 \%)$ and 98105 ha $(29.79 \%)$ in the year 1990, 2000, 2010 and 2018 respectively. This also shows an increasing trend throughout the selected periods. The agriculture land covered an area of about $81962(24.89 \%)$ in the year 1990 but it is decreased to about 52642 ha $(15.99 \%)$ in the year 2000. If we observe the area covered by agriculture land in the years 2000 and 2010 there is a slight increased agricultural area to about 59116 ha (17.95\%). The area covered by agricultural land in the year 2018 was 34645 ha (10.52\%). As we compare the area between 2010 and 2018 we found a slightly decreasing trend in agricultural land.

Table 1: LULC distribution of Kailali area throughout the selected time periods.

\begin{tabular}{|l|r|r|r|r|}
\hline \multirow{2}{*}{ LULC-classes } & \multicolumn{1}{|c|}{$\mathbf{1 9 9 0}$} & \multicolumn{1}{c|}{$\mathbf{2 0 0 0}$} & \multicolumn{1}{c|}{$\mathbf{2 0 1 0}$} & \multicolumn{1}{c|}{$\mathbf{2 0 1 8}$} \\
\cline { 2 - 5 } & Area (\%) & Area (\%) & Area (\%) & Area (\%) \\
\hline Water Bodies & 2.00 & 0.97 & 0.90 & 1.51 \\
\hline Vegetation & 48.39 & 54.22 & 50.81 & 53.74 \\
\hline Settlement & 1.46 & 2.83 & 3.38 & 4.44 \\
\hline Bare Land & 23.25 & 25.99 & 26.96 & 29.79 \\
\hline Agriculture & 24.89 & 15.99 & 17.95 & 10.52 \\
\hline Total & 100 & 100 & 100 & 100 \\
\hline
\end{tabular}

The land use and land cover classes, over the past 40 years (1990-2018) as shown in Table 1, where settlement, bare land, and vegetation is increased by $204 \%, 28 \%$, and $11 \%$ respectively. On the other hand water bodies and agriculture is decreased by $24 \%$ and $57 \%$. Table 1 and Figure $2 \& 3$ also shows the fluctuating pattern of vegetation agriculture and water bodies in which the areas decreases and increases as time goes on. The settlement and bare land area throughout the selected periods have increasing trends. It is found that agricultural land is highly affected which signifies rapid population growth and urbanization in this area.

The land use and land cover changes trends between 1990 to 2000 and 2000 to 2010 were found quite similar. Land use and land cover changes trends show several ecological, physical and socioeconomic consequences. These consequences have positive as well as negative sides. The positive side represents an increase in agriculture land may raise food production for a growing population but it does not guarantee how productive the last exploited lands into agriculture. The negative side means changing vegetation to agricultural land signifies change the radiation balance of the given unit of area. 

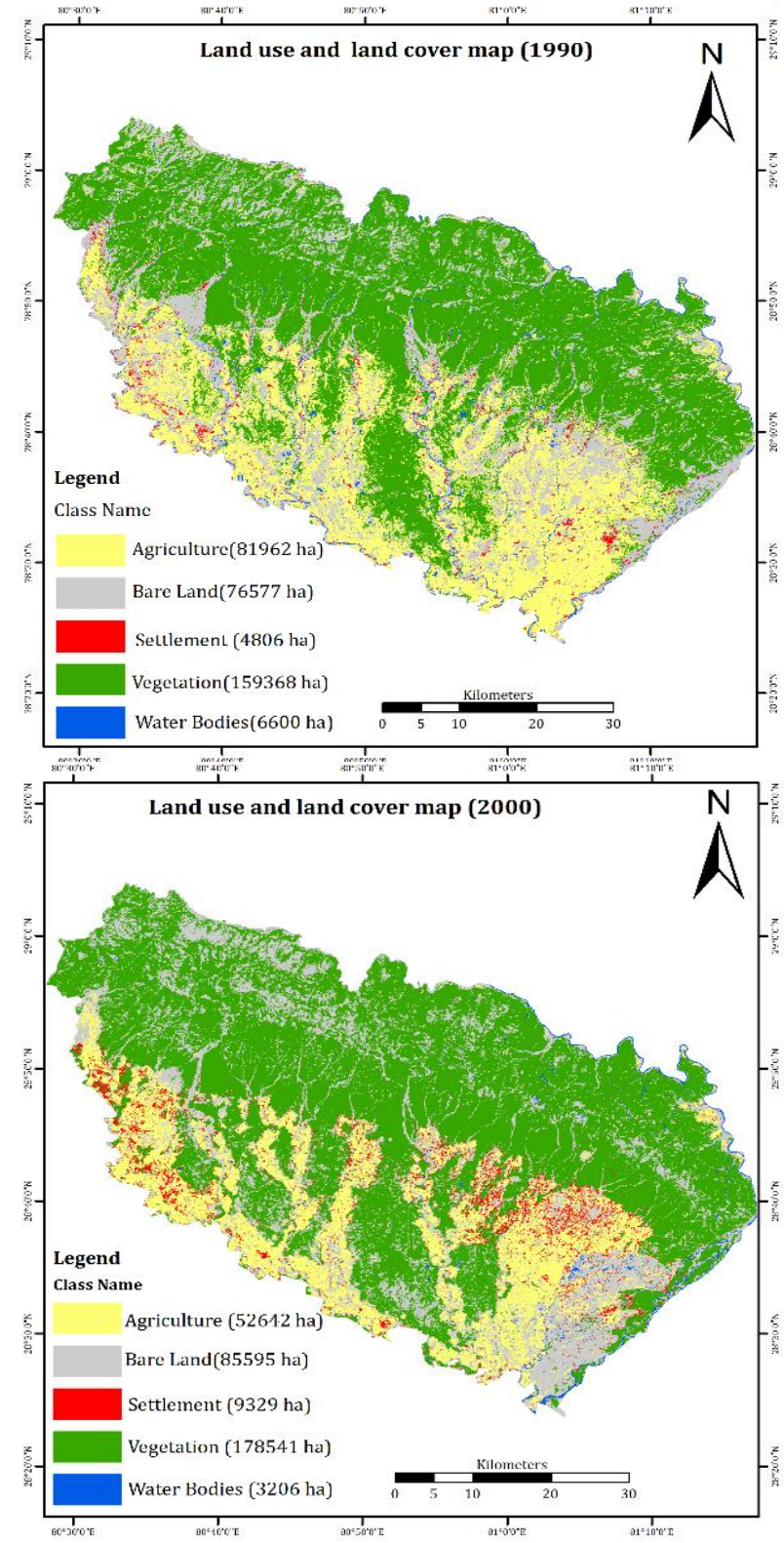

Figure 2: LULC map of Kailali District for years 1990, 2000.

As we know, Albedo value increases in the urban area (surface without vegetation) this means throughout the year producing more incident radiation to reflect the space. Another negative side is environmental consequences as vegetation is converted into Agricultural land, bare land and settlement, the porosity of soil may be reduced by soil compaction results in decreasing infiltration capacity and increasing soil erosion (Brussaard, 1994; Don et al., 2011). In the hilly region of Kailali district, the conversion of the vegetation to agricultural lands decreases due to controlled habitat fragmentation being less urbanized as compared to the Terai belt of the district where we can see rapid urbanization with high settlement area. The conversion of the vegetation to agricultural land in the hilly region is also declining because of agriculture land capture less atmospheric moisture than vegetation (Zhang et al., 2015)

LULC distribution among various localities commonly known as Nagarpalikas have been carried out. There are 13 main areas and the variation in these Nagarpalikas is studied and presented.
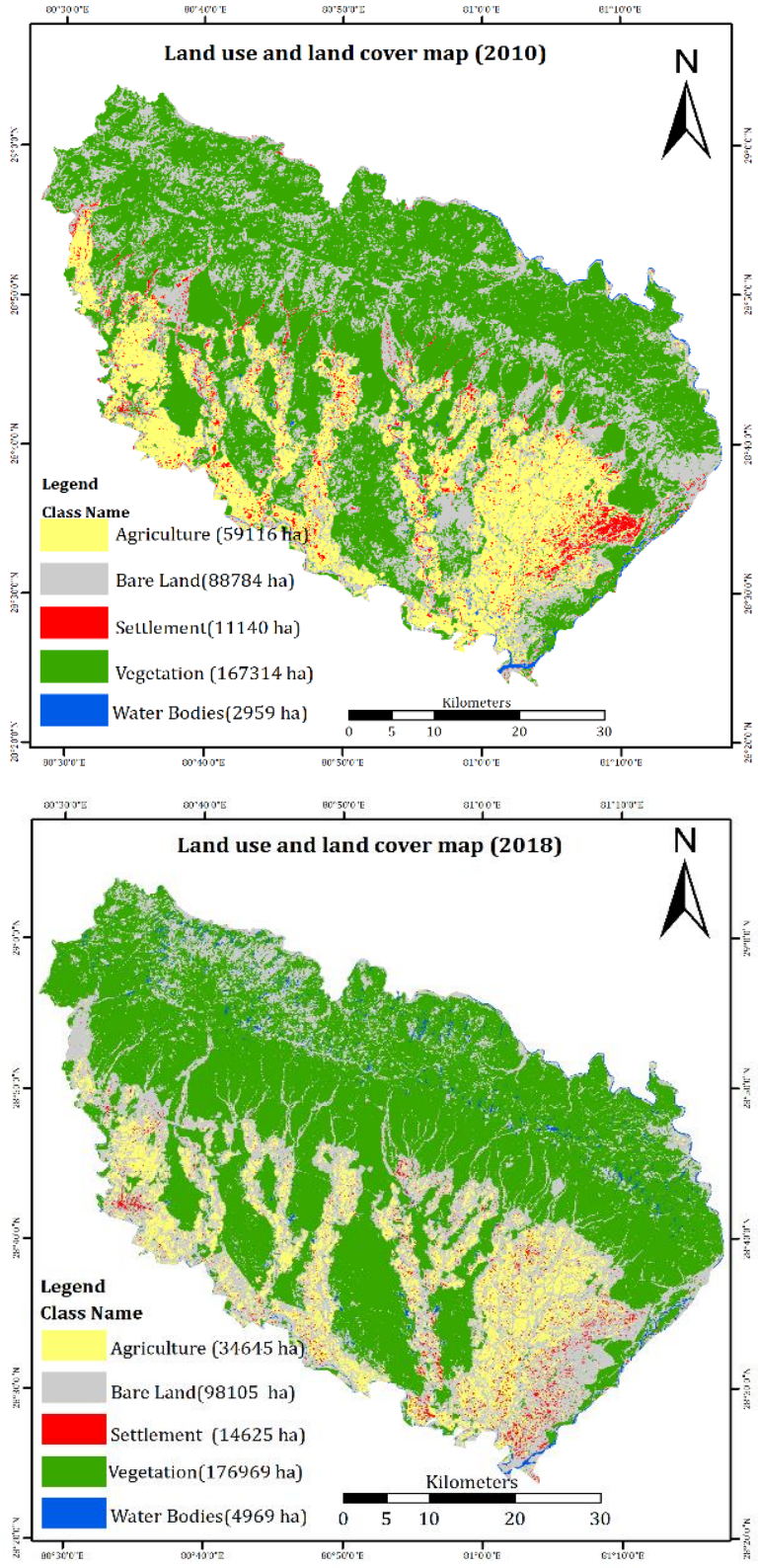

Figure 3: LULC map of Kailali District for years 2010, 2018.

The LULC of Dhangadhi, Tikapur, Mohanyal, and Bardogoriya shows that Dhangadhi and Tikapur have settlement area 1933.924 ha and 772.784 ha respectively and vegetation area 6177.936 ha and 1220.195 ha respectively whereas Bardogoriya and Mohanyal have settlement area 118.494 ha and 77.22 ha respectively and vegetation area 1286.766 ha and 49208.046 ha respectively as shown in Figure 4. The expansion of settlement land is based on its socio-economic development. Figure 4 shows the higher settlement area in Dhangadhi and Tikapur whereas lesser settlement in Mohanyal and Bardogoriya. Dhangadhi and Tikapur are the major cities of Kailali district whereas Mohanyal and Bardogoriya are rural regions of Kailali district. This observation indicates the rapid urbanization and complex spatiotemporal phenomenon seen in Dhangadhi and Tikapur in recent years as compared to Bardogoriya and Mohanyal. The local units which have a higher number of households and populations are urbanized area where we can see the higher settlement and bare land as compared to others. The units which are highly urbanized are Dhangadhi, Kailali, and Gauriganga there we can see high populations with greater 
settlement region as compared to those units where development is less such as Mohanyal gaunpalika, Bardogoria gaupalika, and Chure gaunpalika. In the year 2010 Dhangadhi, Kailari and Gauriganga are the local units that have greater populations and households as compared to others.

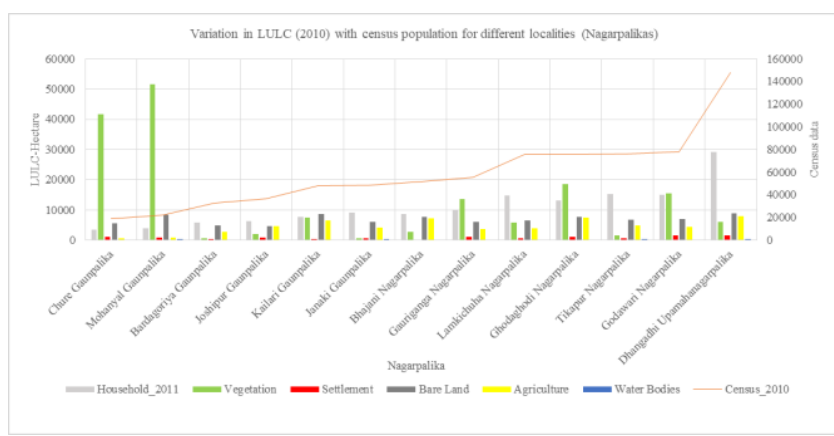

Figure 4: Variation in LULC (2010) with census population for different localities (Nagarpalikas)

\subsection{Accuracy Assessment}

Error matrix is generated through user accuracy (UA), producer accuracy (PA), overall accuracy and kappa statistics is evaluated to validate the classified LULC map of different years with Google earth and Sentinel-2 data (10, 20m spatial resolution). The research is assumed to be partially representing the ground condition if the overall accuracy is above $80 \%$ and kappa statistics is close to value 1 . The detail of accuracy assessment as shown in Table 2 that illustrates the overall accuracy, producer accuracy, user accuracy and kappa statistics of classified data. The overall accuracy is $88 \%, 86 \%, 86 \%$ and $89 \%$ respectively in the years 1990, 2000, 2010 and 2018. Also, the kappa statistics are $0.85,0.79,0.78$ and 0.9 in the years 1990, 2000, 2010 and 2018 respectively. The overall accuracy and estimated kappa statistics are above $80 \%$ and values closer to 1 respectively signifies that the classified data partially represents the chosen land feature classes.

Table 2: Error matrix showing the accuracy assessment of LULC prepared for different years.

\begin{tabular}{|l|r|c|r|r|r|r|r|r|}
\hline \multirow{2}{*}{ LULC Class } & \multicolumn{2}{|c|}{ 1990(\%) } & \multicolumn{2}{|c|}{ 2000(\%) } & \multicolumn{2}{c|}{ 2010(\%) } & \multicolumn{2}{|c|}{ 2018(\%) } \\
\cline { 2 - 10 } & PA & UA & PA & UA & PA & UA & PA & UA \\
\hline Water Bodies & 93 & 87 & 88 & 91 & 86 & 89 & 83 & 80 \\
\hline Vegetation & 87 & 93 & 81 & 79 & 96 & 92 & 90 & 92 \\
\hline Settlement & 67 & 94 & 50 & 66 & 62 & 83 & 76 & 86 \\
\hline Bare Land & 85 & 75 & 90 & 90 & 50 & 66 & 84 & 80 \\
\hline Agriculture & 79 & 80 & 73 & 89 & 86 & 75 & 78 & 85 \\
\hline $\begin{array}{c}\text { Overall } \\
\text { Accuracy (\%) }\end{array}$ & \multicolumn{2}{|c|}{88} & \multicolumn{2}{|c|}{86} & 86 & \multicolumn{2}{|c|}{89} \\
\hline $\begin{array}{c}\text { Kappa } \\
\text { Statistics }\end{array}$ & 0.8582 & 0.7994 & 0.7831 & \multicolumn{2}{|c|}{0.9} \\
\hline
\end{tabular}

The producer's accuracy specifies how accurately a specified LULC class has been classified. The maximum producer accuracy obtained from the error matrix as shown in Table 2 for the years 1990, 2000, 2010 and 2018 is $93 \%$ in water bodies, $90 \%$ in a settlement, $96 \%$ in bare land and $90 \%$ in vegetation. Similarly, maximum producer accuracy obtained for the years 1990, 2000, 2010 and 2018 is $67 \%$ in a settlement, $50 \%$ in a settlement, $50 \%$ in bare land and $76 \%$ in a settlement.
The user's accuracy represents the efficiency of the LULC map and states how effectively the LULC map represents the ground reality. The user accuracy for the year 1990,2000,2010 and 2018 shows the maximum percentage for vegetation is $93 \%$, water bodies are $91 \%$, vegetation is $92 \%$ and vegetation is $92 \%$ respectively. Similarly, the minimum percentage of user accuracy is $75 \%$ for bare land in the year 1990, $66 \%$ for settlement in the year 2000, 66\% for bare land in the year 2010 and $80 \%$ for bare land in the year 2010

\section{CONCLUSIONS}

The work analysed the spatiotemporal dynamics of land use and land cover using satellite imagery to understand the situation of the agricultural area of different periods of Kailali district of Nepal. It was observed that from 1990-2000-2010-2018 major changes were found in settlement, vegetation and agricultural classes. The settlement area is increased by $204 \%$; vegetation is increased by $11 \%$; bare land is increased by $28 \%$; whereas water bodies are decreased by $24 \%$ and agriculture is decreased by $57 \%$. The changes in LULC show that settlement and bare land is continuously increasing throughout these years. The decrease in agricultural land and increase in the settlement area are highly affected by urbanization in this area which are mainly observed in Dhangadhi, Kailari and Gauriganga nagarpalikas. These nagarpalikas have the highest population leading to urbanization and thus decrease in agricultural areas.

There are several recommendations based upon the conclusion of the research for the proper management, conservation, and monitoring of land resources:

- Government officials should collaborate with nongovernmental institutions for conserving and planting trees.

- Effective agriculture management practices and policies should be carried out at the government level for minimizing agriculture resources degradation by the human-induced impact.

- The vegetation and natural resources would be protected and restored efficiently and effectively depend upon the incentives provided to local people to look after the new plantations.

\section{ACKNOWLEDGEMENTS}

The authors would like to express our sincere gratitude towards IIT Mandi, Kamand, Himachal Pradesh, India for providing us this platform and technical resources for carrying out this study. We would also like to thank the United States Geological Survey and Mountain of Central Asia Digital Dataset (MCADD) for providing the data to carry out this research.

\section{REFERENCES}

Brussaard, L. (1994). Interrelationships between biological activities, soil properties and soil management. In Soil resilience and sustainable land use (pp. 309-329).

Dadras, M., Shafri, H. Z., Ahmad, N., Pradhan, B., \& Safarpour, S. (2015). Spatio-temporal analysis of urban growth from remote sensing data in Bandar Abbas city, Iran. The Egyptian Journal of Remote Sensing and Space Science, 18(1), 35-52. 
DeFries, R. S., Foley, J. A., \& Asner, G. P. (2004). Land-use choices: Balancing human needs and ecosystem function. Frontiers in Ecology and the Environment, 2(5), 249257.

Don, A., Schumacher, J., \& Freibauer, A. (2011). Impact of tropical land-use change on soil organic carbon stocks-a meta-analysis. Global Change Biology, 17(4), 1658-1670.

FAO, (1976). A framework for Land Evaluation. FAO Soils Bulletin, 32.

Foley, J. A., Defries, R., Asner, G. P., Barford, C., Bonan, G., Carpenter, S. R., ... \& Helkowski, J. H. (2005). Review global consequences of land use.

Halmy, M. W. A., Gessler, P. E., Hicke, J. A., \& Salem, B. B. (2015). Land use/land cover change detection and prediction in the north-western coastal desert of Egypt using MarkovCA. Applied Geography, 63, 101-112.

Herold, M., Goldstein, N. C., \& Clarke, K. C. (2003). The spatiotemporal form of urban growth: measurement, analysis and modeling. Remote sensing of Environment, 86(3), 286-302.

Guan, D., Li, H., Inohae, T., Su, W., Nagaie, T., \& Hokao, K. (2011). Modeling urban land use change by the integration of cellular automaton and Markov model. Ecological Modelling, 222(20-22), 3761-3772.

Janssen, L. L. F., \& Gorte, B. G. H. (2001). Principle of Remote Sensing, chapter 12 Digital image classification. International Institute for Aerospace survery and Earth Science, ITC, Enschede, The Netherlands.

Gupta, S. K., \& Shukla, D. P. (2016). Assessment of land use/land cover dynamics of Tso Moriri Lake, a Ramsar site in India. Environmental monitoring and assessment, 188(12), 700.

Jat, M. K., Garg, P. K., \& Khare, D. (2008). Monitoring and modelling of urban sprawl using remote sensing and GIS techniques. International journal of Applied Earth Observation and Geoinformation, 10(1), 26-43.

Joshi, R. N. (2016). Prospects and Problems of Tourism In Kailali District (Doctoral dissertation, Central Department of Rural Development (CDRD) Tribhuvan University, Kirtipur, Kathmandu, Nepal).

Lillesand, T., Kiefer, R. W., \& Chipman, J. (2015). Remote sensing and image interpretation. John Wiley \& Sons.

Martinuzzi, S., Gould, W. A., \& Gonzalez, O. M. R. (2007). Land development, land use, and urban sprawl in Puerto Rico integrating remote sensing and population census data. Landscape and Urban Planning, 79(3-4), 288-297.

Mas, J. F. (1999). Monitoring land-cover changes: a comparison of change detection techniques. International journal of remote sensing, 20(1), 139-152.

Meyer, W. B., \& Turner, B. L. (1992). Human population growth and global land-use/cover change. Annual review of ecology and systematics, 23(1), 39-61.
Stomph, T. J., Fresco, L. O., \& Van Keulen, H. (1994). Land use system evaluation: concepts and methodology. Agricultural systems, 44(3), 243-255.

Taubenböck, H., Wegmann, M., Roth, A., Mehl, H., \& Dech, S. (2009). Urbanization in India-Spatiotemporal analysis using remote sensing data. Computers, environment and urban systems, 33(3), 179-188.

Williams, K. J., \& Schirmer, J. (2012). Understanding the relationship between social change and its impacts: The experience of rural land use change in south-eastern Australia. Journal of Rural Studies, 28(4), 538-548.

Wilson, B., \& Chakraborty, A. (2013). The environmental impacts of sprawl: emergent themes from the past decade of planning research. Sustainability, 5(8), 3302-3327.

Zhang K, Dang H, Zhang Q, Cheng X., 2015. Soil carbon dynamics following land-use change varied with temperature and precipitation gradients: evidence from stable isotopes. Glob Chang Biol 21(7):2762-2772

Zubair, A. O. (2006). Change detection in land use and Land cover using remote sensing data and GIS (A case study of Ilorin and its environs in Kwara State). Department of Geography, University of Ibadan, 176. 